\title{
Contaminação ambiental por Bacillus cereus em unidade de alimentação e nutrição
}

\author{
Food service environmental contamination \\ by Bacillus cereus
}

Renata Aparecida MENDES ${ }^{1}$

Raquel Monteiro Cordeiro de AZEREDO²

Ana Íris Mendes COELHO²

Selma Silva de OLIVEIRA ${ }^{3}$

Maria do Socorro Lira COELHO ${ }^{4}$

\section{R E S U M O}

Este trabalho foi realizado em uma Unidade de Alimentação e Nutrição de uma universidade pública, em Viçosa, MG, tendo como objetivo contribuir para a avaliação de riscos a que se expõem os usuários de cozinhas institucionais semelhantes, por meio da avaliação do potencial que superfícies de bancadas de aço inox representam como fontes de contaminação dos alimentos por Bacillus cereus. A presença do microorganismo em superfícies de 24 bancadas que eventualmente entram em contato com alimentos crus e cozidos foi analisada em duas ocasiões distintas, por meio da técnica do swab e semeadura em placas contendo meio MYP. A presença do microorganismo não foi detectada em $73 \%$ das amostras. Entre aquelas

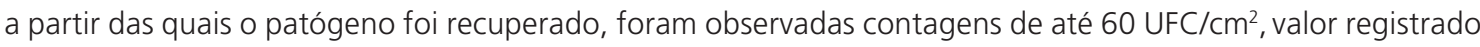
no setor de pré-preparo de vegetais. A simples presença do patógeno reforça a necessidade de higienização adequada, especialmente em locais onde a contaminação pode atingir alimentos prontos para consumo, de forma a prevenir a ocorrência de surtos de doenças de origem alimentar devidas a esse microorganismo.

Termos de indexação: Bacillus cereus, contaminação bacteriana, higiene, microbiologia de alimentos, alimentação institucional.

\footnotetext{
1 Bolsista de Iniciação Científica, Curso de Nutrição, Universidade Federal de Viçosa.

2 Departamento de Nutrição e Saúde, Curso de Nutrição, Universidade Federal de Viçosa. Av. P.H. Rolfs, s/n, Campus Universitário, 36571-000, Viçosa, MG, Brasil. Correspondência para/Correspondence to: R.M.C. AZEREDO. E-mail: razeredo@ufv.br

3 Estudante, Curso de Nutrição, Universidade Federal de Viçosa.

4 Técnica de Nível Superior, Departamento de Nutrição e Saúde, Universidade Federal de Viçosa.
} 


\section{A B S T R A C T}

This study reports an evaluation performed at Food Service Federal University Viçosa in Southeast Brazil, as a contribution to estimate the risks that users of similar public food services are exposed to, by identifying environmental surface areas from which Bacillus cereus may be transferred to food. Samples have been collected in order to evaluate the environmental contamination, using the "swab" technique and surface platting in MYP agar, for expressing the number of CFU/ $\mathrm{cm}^{2}$ in 24 stainless steel tables that may have contact with raw or cooked foods. Each table was analyzed twice. Although some samples did not exhibit contamination

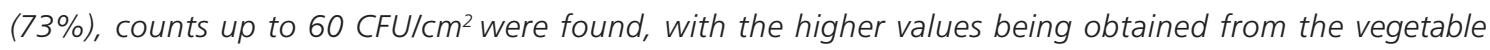
pre-preparation section samples. The presence of this pathogen reinforces the need of using adequate sanitary procedures, especially in places where contamination may occur in ready to eat foods, in order to prevent food borne disease outbreaks due to the microrganism.

Index terms: Bacillus cereus, bacterial contamination, hygiene, food microbiology, institutional feeding.

\section{N T R O D U Ç Ã O}

Alimentos preparados em Unidades de Alimentação e Nutrição (UAN) têm sido freqüentemente envolvidos em surtos de intoxicação e infecção alimentar ${ }^{1}$. Registros epidemiológicos revelam que a maioria dos surtos de doenças de origem alimentar diagnosticados é atribuída a patógenos veiculados por alimentos preparados nesses locais ${ }^{2}$. Ainda que o número de surtos registrados seja subestimado, sua relevância é reconhecida. Tais surtos originam-se da contaminação de alimentos por uma vasta gama de microorganismos, dentre os quais Bacillus cereus, uma bactéria Gram-positiva, anaeróbia facultativa, em forma de bastonete, formadora de esporos, que apresenta motilidade ${ }^{3,4}$ que tem sido reconhecida como agente etiológico de doenças de origem alimentar há mais de 40 $a_{0}{ }^{5}$. Em se tratando desse microorganismo em particular, os relatos de doenças de origem alimentar que the são atribuídos são escassos, com muitas ocorrências não suspeitas ou não confirmadas ${ }^{6}$.

Este microorganismo tem o solo como o seu reservatório natural. Entretanto, devido à resistência de seus esporos, a bactéria pode ser isolada de uma grande variedade de pontos, estando amplamente distribuída na natureza ${ }^{5,7}$. Por esta razão, contamina facilmente alimentos como vegetais, cereais, condimentos, carne bovina, suína e de frango, laticínios, sorvetes, pudins, carne cozida, sopas, pratos à base de vegetais e arroz cozido ${ }^{3}$. A contaminação de alimentos por $B$. cereus constitui não somente uma importante causa de deterioração, mas também está associada com a ocorrência de dois tipos de síndrome, devidos à ingestão de alimentos contaminados com cepas patogênicas produtoras de toxinas, uma emética, outra diarréica $7,8,9,10$. A toxina do tipo emético é pré-formada no alimento, enquanto a do tipo diarréico é, muito possivelmente, produzida no trato intestinal, sendo os fatores de virulência ainda não completamente caracterizados $5^{5,7,11}$.

A síndrome diarréica é caracterizada basicamente por dor abdominal, diarréia aquosa e tenesmos retais que ocorrem entre 8 e 16 horas após a ingestão do alimento contaminado (normalmente $>10^{5}$ microorganismos/g). Náuseas e vômitos, iniciando de 1 a 5 horas após a ingestão de alimento que contenha via de regra, $>10^{7}$ microorganismos/g, caracterizam a síndrome emética $^{3,7}$.

A grande capacidade de multiplicação de $B$. cereus em diferentes substratos tem sido amplamente constatada e registrada na literatura. A simples presença do patógeno em locais e condições que possibilitem sua eventual transferência para alimentos prontos é, reconhe- 
cidamente, um fator importante para desencadear episódios de intoxicações - muitos dos quais sequer vêm a ser diagnosticados ${ }^{12}$.

Considerando suas características de disseminação, resistência de esporos e patogenicidade, o problema assume uma importância expressiva quando os produtos contaminados são destinados a milhares de pessoas, diariamente, como é o caso de restaurantes de instituições ou indústrias. Assim, o trabalho descrito foi desenvolvido com o propósito de contribuir para a prevenção de surtos de doenças de origem alimentar atribuídos a $B$. cereus, avaliando uma típica unidade institucional de alimentação, com relação a pontos ambientais onde se realizam operações de pré-preparo e preparo de alimentos. Nesses locais, as grandes quantidades de alimentos produzidas passam, freqüentemente, por lentas operações de resfriamento ou por períodos de espera, pós-cozimento, suficientemente longos para permitir que as populações microbianas alcancem níveis perigosos. Tal consideração ressalta a importância de se identificar os pontos do ambiente que possam representar fontes de contaminação, de forma a orientar medidas efetivas de controle do patógeno, em particular possíveis ações corretivas em processos de higienização.

\section{MATERIALE MÉTODOS}

O trabalho foi realizado em uma Unidade de Alimentação e Nutrição (UAN) de uma universidade pública, em Viçosa, MG. Avaliou-se a contaminação das superfícies de 24 bancadas de aço inoxidável, localizadas em diversos setores da UAN: bancadas dos setores de estocagem, seleção de grãos, pré-preparo (carnes, vegetais e massas), cocção, montagem e distribuição dos alimentos. Utilizou-se a técnica de coleta por swabs e foram adotados procedimentos oficiais da Association of Official Analytical Chemists de 1992 (AOAC) $)^{13}$ para a remoção dos microorganismos.
Os swabs foram esterilizados a $121^{\circ} \mathrm{C}$ por 15 minutos, mergulhados em tubos contendo $10 \mathrm{~mL}$ de água peptonada a $0,1 \%(\mathrm{p} / \mathrm{v})$, também esterilizada, e friccionados na superfície das bancadas a um ângulo de $30^{\circ}$, percorrendo cinco áreas de $50 \mathrm{~cm}^{2}$ em cada bancada, por três vezes consecutivas, mudando a direção ao final de cada passagem. A seguir, cada swab foi devolvido ao tubo com água peptonada, sendo a parte manuseada quebrada e descartada. As coletas foram desenvolvidas sempre posteriormente à higienização das bancadas, após o almoço, e antes de se iniciarem as atividades de preparo do jantar. Tomou-se a precaução de não interferir nos procedimentos habituais dos funcionários. Tais coletas foram feitas em duas ocasiões distintas, nos meses de outubro-novembro de 1999 (primeira coleta) e julho-agosto de 2000 (segunda coleta) totalizando, assim, 48 amostras.

As amostras foram imediatamente levadas ao laboratório onde foram preparadas diluições decimais seriadas com semeadura em placas de Petri contendo ágar vermelho de fenol-gema de ovo-manitol-polimixina B (Ágar MYP ou meio de Mossel). Após a incubação a $30^{\circ} \mathrm{C}$ por 18 a 24 horas, foram feitos a contagem e isolamento de exemplares típicos de $B$. cereus. $O$ isolamento e a confirmação dos isolados foram feitos de acordo com a metodologia proposta pela FDA, descrita por Azeredo ${ }^{12}$. Os resultados das contagens foram expressos em Unidades Formadoras de Colônia por $\mathrm{cm}^{2}\left(\mathrm{UFC} / \mathrm{cm}^{2}\right)$.

\section{RESULTADOS E DISCUSS Ã O}

A análise dos dados evidenciou a presença de $B$. cereus em $27 \%$ do total de amostras de bancadas analisadas (Tabela 1), sendo o setor de preparo de massas o único ponto onde não houve o isolamento do microorganismo (Figura 1). Os valores encontrados expressaram desde a não detecção do microorganismo até uma contagem de $60 \mathrm{UFC} / \mathrm{cm}^{2}$ (Tabela 1). Tal contagem foi observada exatamente em uma bancada localizada no setor de pré-preparo de vegetais, local 
onde se manipulam alimentos que, na maioria das vezes, não recebem tratamento térmico de acabamento. Na maioria dos casos, os números encontrados ficaram abaixo de $2 \mathrm{UFC} / \mathrm{cm}^{2}$, limite máximo recomendado por Sveum et al. ${ }^{14}$ para a contagem de microorganismos mesófilos aeróbios em superfícies de processamento de alimentos. Em quatro amostras (8,3\%), os resultados encontrados foram superiores a esse valor. Considerando a patogenicidade desse microorganismo, sua capacidade de multiplicação em ampla faixa de temperatura, possivelmente esse limite - em se tratando de $B$. cereus - revele uma tolerância que merece ser revista.

Os resultados observados quanto à presença de $B$. cereus nos setores estudados assemelham-se aos registrados por Azeredo et al. ${ }^{15}$ que, em estudo para a detecção e avaliação da incidência de $B$. cereus em amostras de ar coletadas em Unidades de Alimentação e Nutrição, verificaram que em todos os setores analisados de um Restaurante Universitário as amostras coletadas exibiam contaminação pelo microorganismo.

Um estudo de análise de risco, desenvolvido em um restaurante universitário por Nascimento ${ }^{16}$, levou a concluir serem as bancadas do setor de pré-preparo de frutas e hortaliças um ponto crítico expressivo. Esses resultados também são semelhantes àqueles relatados por Rêgo et al. ${ }^{17}$, nos quais se evidenciou que, dentre as áreas que

Tabela 1. Contagens de Bacillus cereus em superfícies de bancadas. Restaurante Universitário, Viçosa, MG, 2000.

\begin{tabular}{|c|c|c|c|c|c|}
\hline \multirow[b]{2}{*}{ Setores } & \multirow[b]{2}{*}{ Bancadas } & \multicolumn{2}{|c|}{ Coleta 1} & \multicolumn{2}{|c|}{ Coleta 2} \\
\hline & & $\mathrm{UFC} / 50 \mathrm{~cm}^{2}$ & $\mathrm{UFC} / \mathrm{cm}^{2}$ & $\mathrm{UFC} / 50 \mathrm{~cm}^{2}$ & $\mathrm{UFC} / \mathrm{cm}^{2}$ \\
\hline Estocagem & 1 & - & - & 20 & 0,40 \\
\hline Seleção de grãos & 1 & - & - & $2,67 \times 10^{2}$ & 5,33 \\
\hline \multirow[t]{4}{*}{ Pré-preparo de carnes } & 1 & - & - & 20 & 0,40 \\
\hline & 2 & - & - & - & - \\
\hline & 3 & - & - & - & - \\
\hline & 4 & - & - & - & - \\
\hline \multirow[t]{7}{*}{ Pré-preparo de vegetais } & 1 & 10 & 0,2 & - & - \\
\hline & 2 & 20 & 0,4 & - & - \\
\hline & 3 & - & - & - & - \\
\hline & 4 & 10 & 0,2 & - & - \\
\hline & 5 & - & - & - & - \\
\hline & 6 & - & - & $3 \times 10^{3}$ & 60,00 \\
\hline & 7 & - & - & - & - \\
\hline \multirow[t]{3}{*}{ Pré-preparo de massas } & 1 & - & - & 20 & 0,40 \\
\hline & 2 & - & - & - & - \\
\hline & 3 & 60 & 1,2 & 20 & 0,40 \\
\hline \multirow[t]{3}{*}{ Cocção } & 1 & - & - & - & - \\
\hline & 2 & - & - & $1,05 \times 10^{2}$ & 2,10 \\
\hline & 3 & 5 & 0,1 & - & - \\
\hline \multirow[t]{2}{*}{ Preparo de massas } & 1 & - & - & - & - \\
\hline & 2 & - & - & - & - \\
\hline \multirow[t]{3}{*}{ Distribuição } & 1 & $1,2 \times 10^{2}$ & 2,4 & - & - \\
\hline & 2 & - & - & - & - \\
\hline & 3 & - & - & - & - \\
\hline
\end{tabular}

- a presença da bactéria não foi detectada. 
apresentaram elevados níveis de contamina-ção, destacaram-se as áreas de preparação de frutas e hortaliças. Entretanto, Azeredo et al. ${ }^{15}$ encontraram níveis mais altos de contaminação pelo microorganismo nos setores de cocção e distribuição.

$\mathrm{O}$ isolamento do microorganismo em bancadas dos setores de pré-preparo demonstra a importância desses locais como fontes potenciais de $B$. cereus para o ambiente da Unidade de Alimentação e Nutrição onde o estudo foi realizado, bem como a possibilidade de ocorrer contaminação cruzada para os alimentos. Vale ressaltar que a contaminação cruzada é freqüentemente relatada como fator responsável pela ocorrência de enfermidade de origem alimen$\operatorname{tar}^{18,19}$. A bactéria pode ser transferida para os alimentos, a partir destas fontes, e aí sobreviver, em forma de esporos, a tratamentos térmicos que reduzem a população competitiva, o que Ihe proporciona condições ideais de multiplicação, podendo resultar em surto de doença de origem alimentar ${ }^{11}$. A característica de formar esporos torna o microorganismo resistente à inativação por métodos químicos, irradiação ou tratamentos térmicos, sendo que esta capacidade de sobrevivência torna a bactéria um problema em todos os setores de processamento de alimentos ${ }^{9}$.
A legislação brasileira não estabelece limites para a contagem de microorganismos em superfícies de processamento de alimentos ${ }^{1}$. Enquanto Sveum et al. ${ }^{14}$ propõem $2 \mathrm{UFC} / \mathrm{cm}^{2}$, para aeróbios mesófilos, Silva Jr. ${ }^{18}$ recomenda, para equipamentos e utensílios de preparação - dentre os quais podem ser incluídas as bancadas de manipulação de alimentos - a ausência de $B$. cereus em $50 \mathrm{~cm}^{2}$ da amostra. Considerando este autor, 27\% das amostras analisadas encontravamse fora da recomendação.

Embora muitos considerem baixos os riscos de intoxicações por esse patógeno, Doyle ${ }^{20}$ alerta para o fato de que o problema pode ser agravado quando os alimentos, especialmente aqueles previamente cozidos - desprovidos da maioria dos competidores - são mantidos a temperaturas entre $10^{\circ} \mathrm{C}$ e $55^{\circ} \mathrm{C}$ por períodos maiores do que duas horas. Num estudo realizado para investigar as causas de um surto ocorrido na Itália, que envolvia 173 pessoas com sintomas de intoxicação (náusea e diarréia aquosa), os autores identificaram $B$. cereus como o agente etiológico e as bancadas de trabalho como fonte de contaminação dos alimentos envolvidos ${ }^{5}$.

Considerando o tempo de geração de aproximadamente 30 minutos, freqüentemente encontrado em exemplares de $B$. cereus, e a

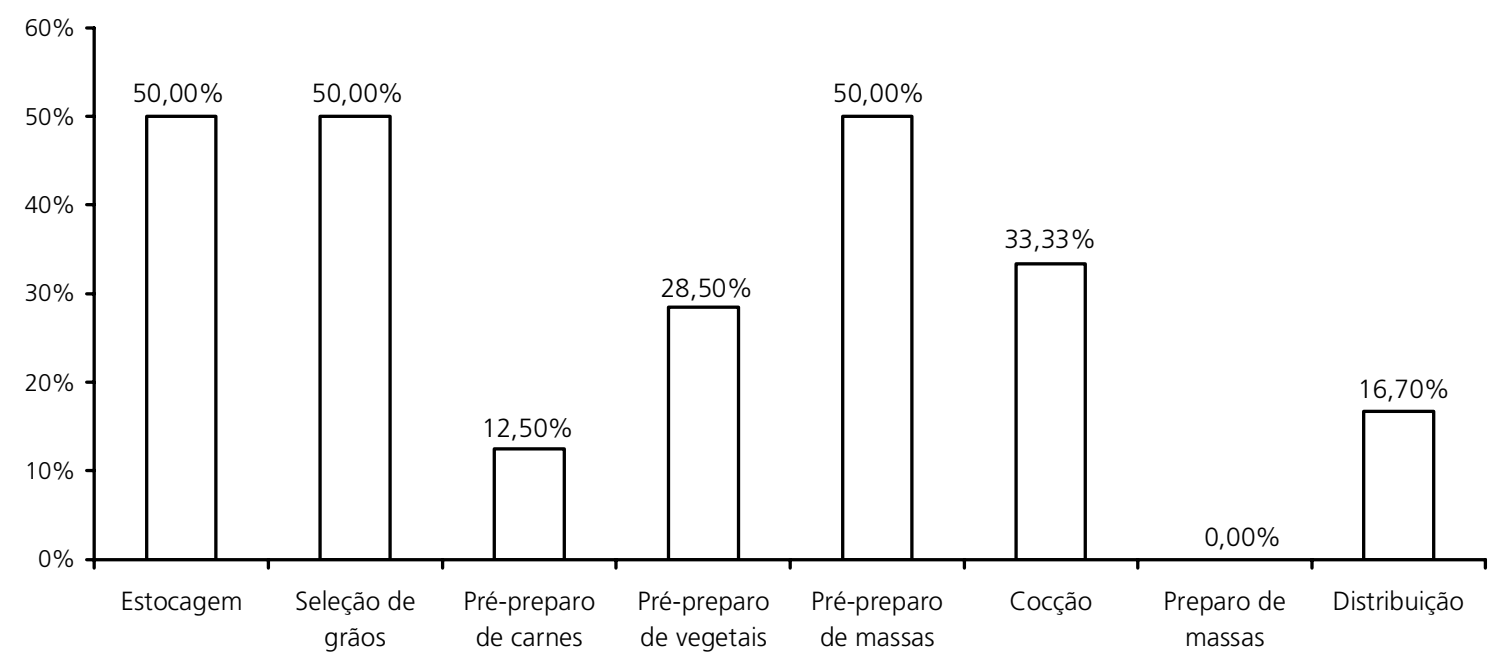

Figura 1. Porcentagens de amostras de bancadas contaminadas com Bacillus cereus. Restaurante Universitário, Viçosa, MG, 2000. 
amplitude da faixa de temperatura que permite seu crescimento, estendendo-se facilmente entre $15^{\circ} \mathrm{C}$ e $45^{\circ} \mathrm{C}$, uma contaminação inicial de $1 \mathrm{UFC} / g$, após um período de 8 horas, pode transformar-se em população de $10^{5} \mathrm{UFC} / \mathrm{g}$, suficiente para causar toxinfecção alimentar ${ }^{12}$. Daí se conclui que a simples detecção do microorganismo no ambiente de uma unidade de alimentação é suficiente para sugerir a adoção de medidas para o seu controle.

\section{O N CLUSÃ O}

No estudo realizado, a detecção de $B$. cereus em superfícies que entram em contato com os alimentos demonstrou a importância desses locais como fontes potenciais de transmissão do microorganismo para o alimento, o que sugere a necessidade de medidas efetivas para o seu controle, principalmente nos locais onde a contaminação pode atingir alimentos prontos para o consumo, nas bancadas dos setores de pré-preparo de vegetais, onde, freqüentemente, são preparados alimentos que não sofrem tratamento térmico.

A simples detecção do microorganismo, em etapas posteriores à higienização e anteriores às operações de manipulação dos alimentos, reforça a importância de procedimentos adequados de sanitização durante todas as etapas do processamento, para prevenir a ocorrência de surtos de doenças de origem alimentar causadas pelo patógeno.

Verifica-se, ainda, a necessidade de uma legislação no Brasil que regulamente padrões aceitáveis de contaminação por $B$. cereus em superfícies de processamento de alimentos.

\section{REFERÊ NCIAS}

1. Lisboa SC. Bactérias Gram-negativas e S. aureus em Serviço de Alimentação Hospitalar [dissertação]. Viçosa, MG: Universidade Federal de Viçosa; 1997.
2. Bryan FL. Hazard Analysis Critical Control Point HACCP. Systems for retail food and restaurant operations. J Food Protec 1990; 53(11):978-83.

3. Harmon SM, Goepfert JM, Bennett RW. Bacillus cereus. In: Vanderzant C, Splittstoesser F. Compendium of methods for the microbiological examination of foods. 3rd ed. Washington DC: American Public Health Association; 1992. p.593-604.

4. Chen CH, Ding HC, Chang TC. Rapid Identification of Bacillus cereus Based on the Detection of a 28,5 Kilodalton Cell Surface Antingen. J Food Protec 2001; 64(3):348-54.

5. Ghelardi E, Celandroni F, Salvetti S, Barsotti C, Baggiani A, Senesi S. Identification and characterization of toxigenic Bacillus cereus isolates responsible for two food-poisoning outbreaks. FEMS Microbiology Letters 2002; 208(1):129-34.

6. Radhika B, Padmapriya BP, Chandrashekar A, Keshava N, Varadaraj MC. Detection of Bacillus cereus in foods by colony hybridization using PCRgenerated probe and characterization of isolates for toxins by PCR. Int J Food Microbiol 2002; 74:131-8.

7. Minnaard J, Humen M, Pérez PF. Effect of Bacillus cereus Exocellular Factors on Human Intestinal Epithelial Cells. J Food Protec 2001; 64(10): 1535-41.

8. Agata N, Ohta M, Yokoyama K. Production of Bacillus cereus emetic toxin (cereulide) in various foods. Int J Food Microbiol 2002; 73:23-7.

9. McElroy DM, Jaykus LA, Foegeding PM. Validation and Analysis of Modeled Predictions of Growth of Bacillus cereus Spores in Boiled Rice. J Food Protec 2000; 63(2):268-72.

10. Tsen HY, Chen ML, Hsieh YM, Sheu SJ, Chen YL. Bacillus cereus Group Strains, their Hemolysin BL Activity, and their Detection in Foods Using a 16s RNA and Hemolysin BL Gene-Targeted Multiplex Polymerase Chain Reaction System. J Food Protec 2000; 63(11):1496-502.

11. Granum PE. Bacillus cereus and its toxins. J Appl Bacteriol 1994; 76 Suppl:61s-6s. 
12. Azeredo RMC. Estimativa de riscos relacionados à contaminação de preparações de arroz por Bacillus cereus [dissertação]. Campinas: Universidade Estadual de Campinas; 1998.

13. Association of Official Analytical Chemists International. Bacteriological Analytical Manual. 7th ed. Arlington; 1992.

14. Sveum WH, Moberg LJ, Rude RA, Frank JF. Microbiological monitoring of the food processing environment. In: Vanderzant C, Splittstoesser F. Compendium of methods for the microbiological examination of foods. 3rd ed. Washington, DC: American Public Health Association; 1992. p.51-74.

15. Azeredo RMC, Soares CM, Kuaye AY, Leitão MFF. Detecção e avaliação da incidência de Bacillus cereus em amostras de ar, coletadas em Unidades de Alimentação e Nutrição. Rev Hig Alim 2001; 15(80/81):135.
16. Nascimento D. Análise de Risco e Pontos Críticos de Controle (ARPCC) de uma Planta de Processamento de Alimentos (Restaurante Universitário) em Ouro Preto-MG. Bol CEPPA 1992; 10(2):170-85

17. Rêgo JC, Guerra NB, Pires EF. Influência do treinamento no Controle Higiênico-sanitário de Unidades de Alimentação e Nutrição. Rev Nutr PUCCAMP 1997; 10(1):50-62.

18. Silva Jr EA. Manual de Controle Higiênico-Sanitário em Alimentos. 4.ed. São Paulo: Varela; 2001.

19. Bryan FL. Risks of practices, procedures and processes that lead to outbreaks of foodborne diseases. J Food Protec 1988; 51(8):663-73.

20. Doyle MP. Bacillus cereus. Food Technol 1988; 42(4):199-200.

Recebido para publicação em 2 de outubro de 2002 e aceito em 25 de junho de 2003. 